Progress Report No. 1

PREPARATION AND PROPERTIES OF EVAPORATED CdTe FILMS

COMPARED WITH SINGLE CRYSTAL CdTe

October 1, 1980 - January 31, 1981

Subcontract No. XW-1-9330-1

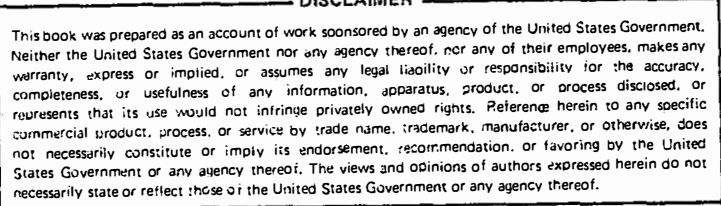

Solar Energy Research Institute

Department of Energy

Golden, Colorado

Richard H. Bube, Principal Investigator

Charles Fortmann and Thomas Thorpe, Graduate Research Assistants

Department of Materials Science and Engineering

Stanford University

Stanford, California 94305 
This program is concerned with the investigation of the materials properties of CdTe thin films deposited by hot-wall vacuum evaporation and of CdTe single crystalline material, particularly those relevant to solar cell applications in which CdTe is the absorbing member.

This report has three main sections: (a) an evaluation of CdTe homojunctions formed by HWVE of CdTe by Walter Huber at the laboratory of $\mathrm{Dr}$. Adolfo Lopez-Otero at the Institut fllr Physik of the University of Linz, using single crystal p-type CdTe from Stanford as a substrate; (b) the design and construction of a HWVE apparatus at Stanford; and (c) properties of grain boundaries in large grain polycrystalline CdTe. 
CdTe HOMOJUNCTIONS

The results described in this section are for CdTe homojunctions prepared by the hot-wall vacuum evaporation (HWVE) of n-type CdTe onto large grain (1 - $2 \mathrm{~mm}$ ) polycrystalline CdTe substrates. The HWVE growth was carried out by Walter Huber in the laboratory of Dr. Adolfo LopezOtero in the Institute for Physics at the University of Linz, Austria, on a substrate grown by the CMR Crystal Growth Laboratory at Stanford University. The HIVE grown n-type layer was deposited at about $500^{\circ} \mathrm{C}$ (substrate temperature) to a thickness of 5 micrometers as measured by an Alpha-step device and by SEM. The surface of the n-type layer was smooth, without texture, and contained some peaks (height less than 1 micrometer). The p-type substrate was about $2 \mathrm{~mm}$ in thickness, with a resistivity of 1-2 ohm-cm and a hole density of about $8 \times 10^{16} \mathrm{~cm}^{-3}$.

The analysis of the junction included the following techniques: light and dark J-V characteristics, EBIC measurements, spectral response of quantum efficiency, and theoretical modeling of the spectral response.

Two cells were prepared. Both cells had an active area of about $0.1 \mathrm{~cm}^{2}$. The back contact consisted of about $1000 \mathrm{~A}$ of gold deposited by vacuum evaporation on a degreased unetched surface. The front contacton one of the cells was formed by the vacuum evaporation of indium on the degreased surface; the other cell had a front contact provided by an indium-gallium solder (commercial). The two cells did not differ significantly in $\mathrm{J}-\mathrm{V}$ characteristics. 


\section{Current-Voltage Characteristics}

The junction properties of the cells were investigated by measurements of the dark J-V characteristics, as shown in Figure 1. The J-V relationship for an ideal diode is given by

$$
\mathrm{J}=\mathrm{J}_{\mathrm{o}}\{\exp (\mathrm{qV} / \mathrm{AkT})-1\}
$$

Figure 2 shows a plot of $1 \mathrm{n} \mathrm{J}$ vs $\mathrm{V}$ for one of the junctions; the behavior is well described by Eq. (I) with $\mathrm{J}_{0}=3 \times 10^{-10} \mathrm{~A} / \mathrm{cm}^{2}$ and $\mathrm{A}=2.2$, suggesting that transport is dominated by recombination/generation processes.

Figure 3 shows the J-V characteristics of the cell under simulated AM1.5 illumination. An open-circuit voltage $\mathrm{V}_{\mathrm{oc}}=0.62 \mathrm{~V}$, and a short-circuit current $\mathrm{J}_{\text {SC }}=0.15 \mathrm{~mA} / \mathrm{cm}^{2}$ are obtained. The low value of the short-circuit current can be attributed to the thick n-type CdTe layer with its strong optical absorption, giving a non-optimized cell structure.

To explore the effects of spreading resistance, the light current $\mathrm{J}_{\mathrm{L}}$ was measured for various intensities of incident light (obtained from the solar simulator with neutral density filters). The results shown in Figure 4 indicate that for the largest currents some loss of current does occur, about a factor of $75 \%$ at full intensity. For currents below about $0.20 \mathrm{~mA} / \mathrm{cm}^{2}$ the response is linear so that the spectral response data to be described later could be corrected linearly for variations in monochromator output.

Figure 3 shows that the light and dark J-V curves cross, indicating that the recombination close to the interface changes with illumination, giving bias-dependent values of $\mathrm{J}_{\mathrm{O}}, A$ and/or $\mathrm{J}_{\mathrm{L}}$. Even with these effects, estimates of $\mathrm{V}_{\text {oc }}$ for optimized $\mathrm{J}_{\mathrm{L}}$ values of $20 \mathrm{~mA} / \mathrm{cm}^{2}$ yield $\mathrm{V}_{\text {oc }}$ in excess of $0.8 \mathrm{~V}$. 


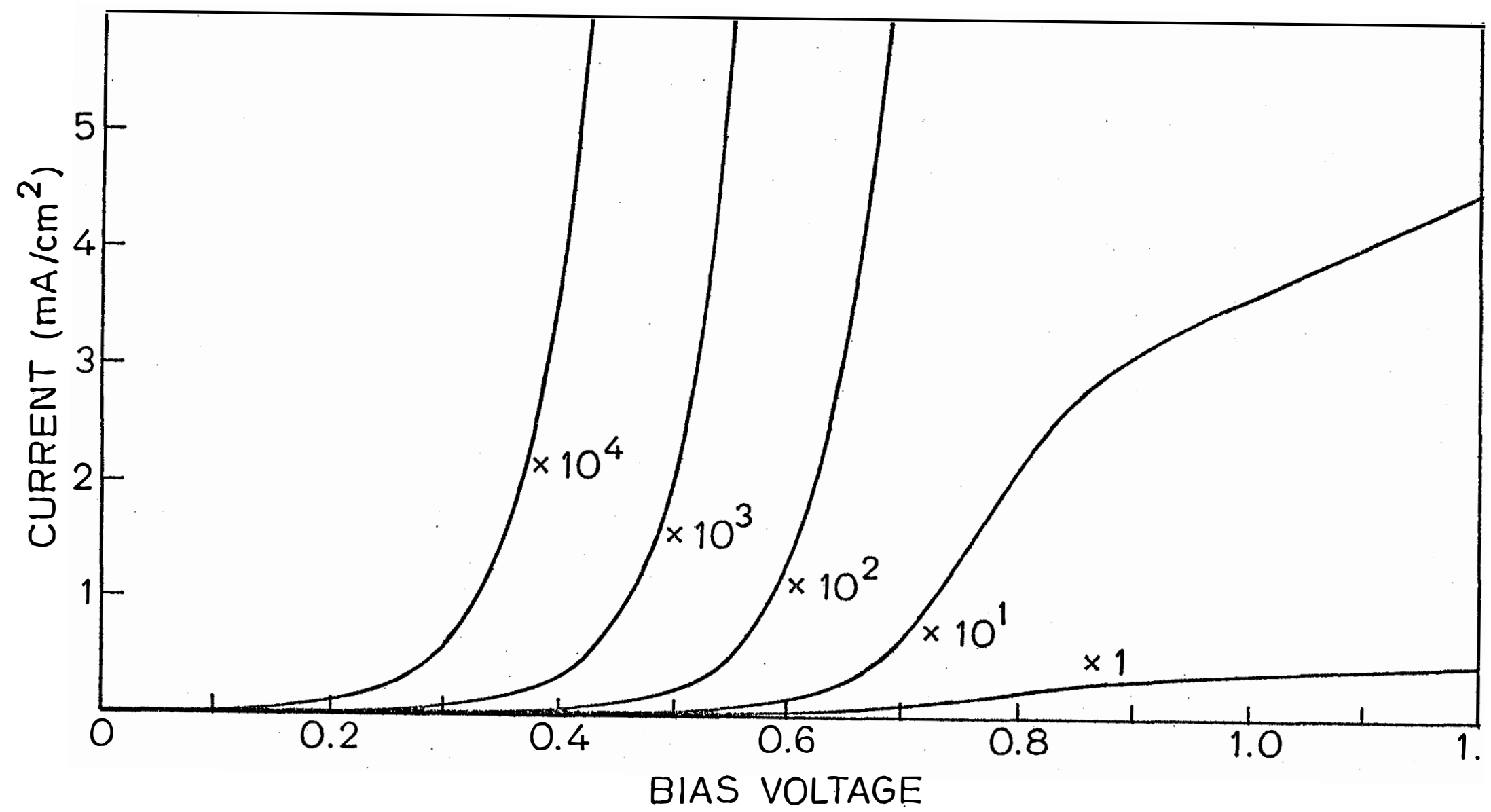

Figure 1. J-V data for a CdTe homojunction prepared by HWVE of n-type CdTe on p-type CdTe substrate. 


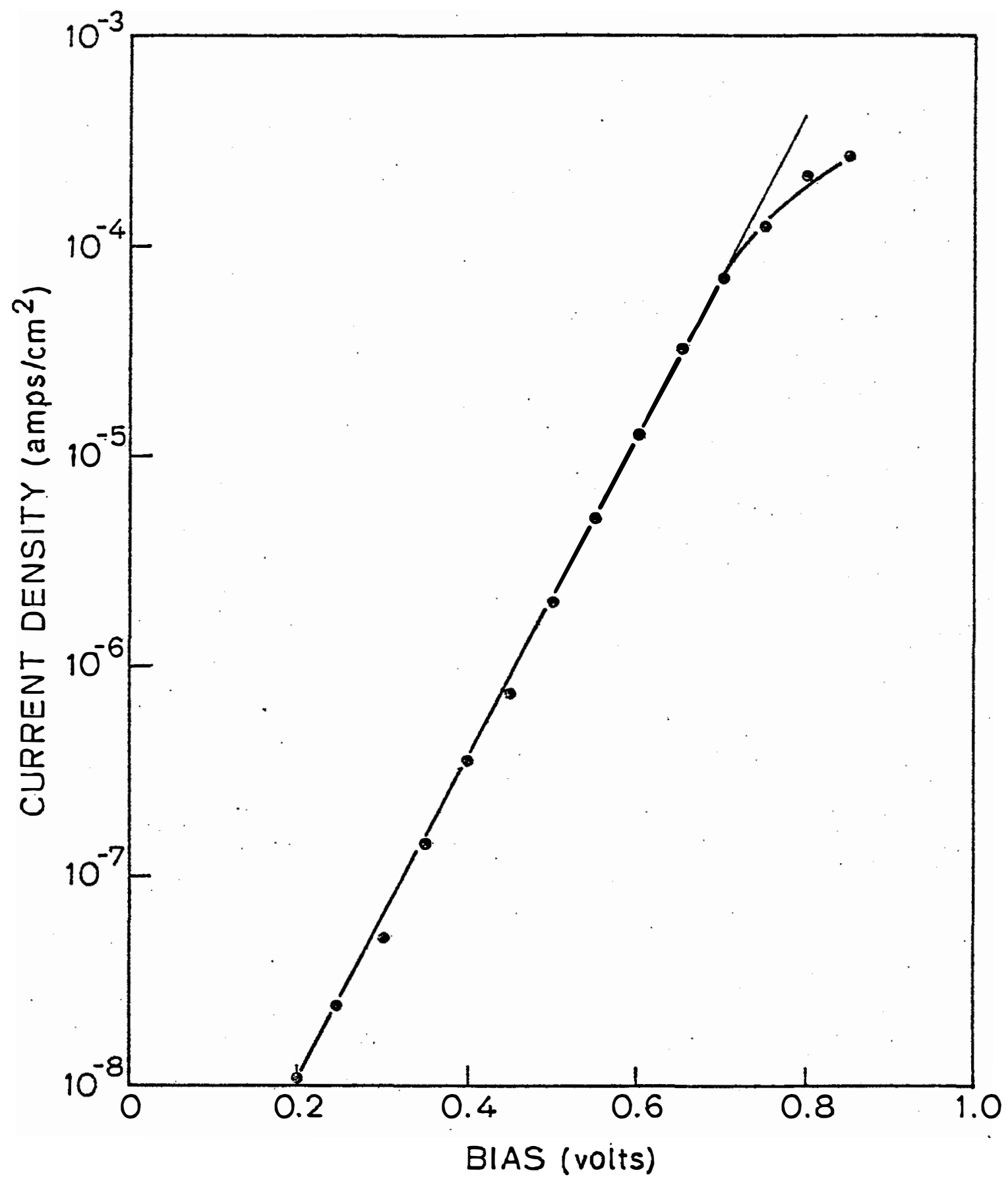

Figure 2. Data of Figure 1 plotted to show relationship of Eq. (1) obeyed. $\mathrm{J}_{\mathrm{O}}=3 \times 10^{-10} \mathrm{~A} / \mathrm{cm}^{2} ; \mathrm{A}=2.2$. 


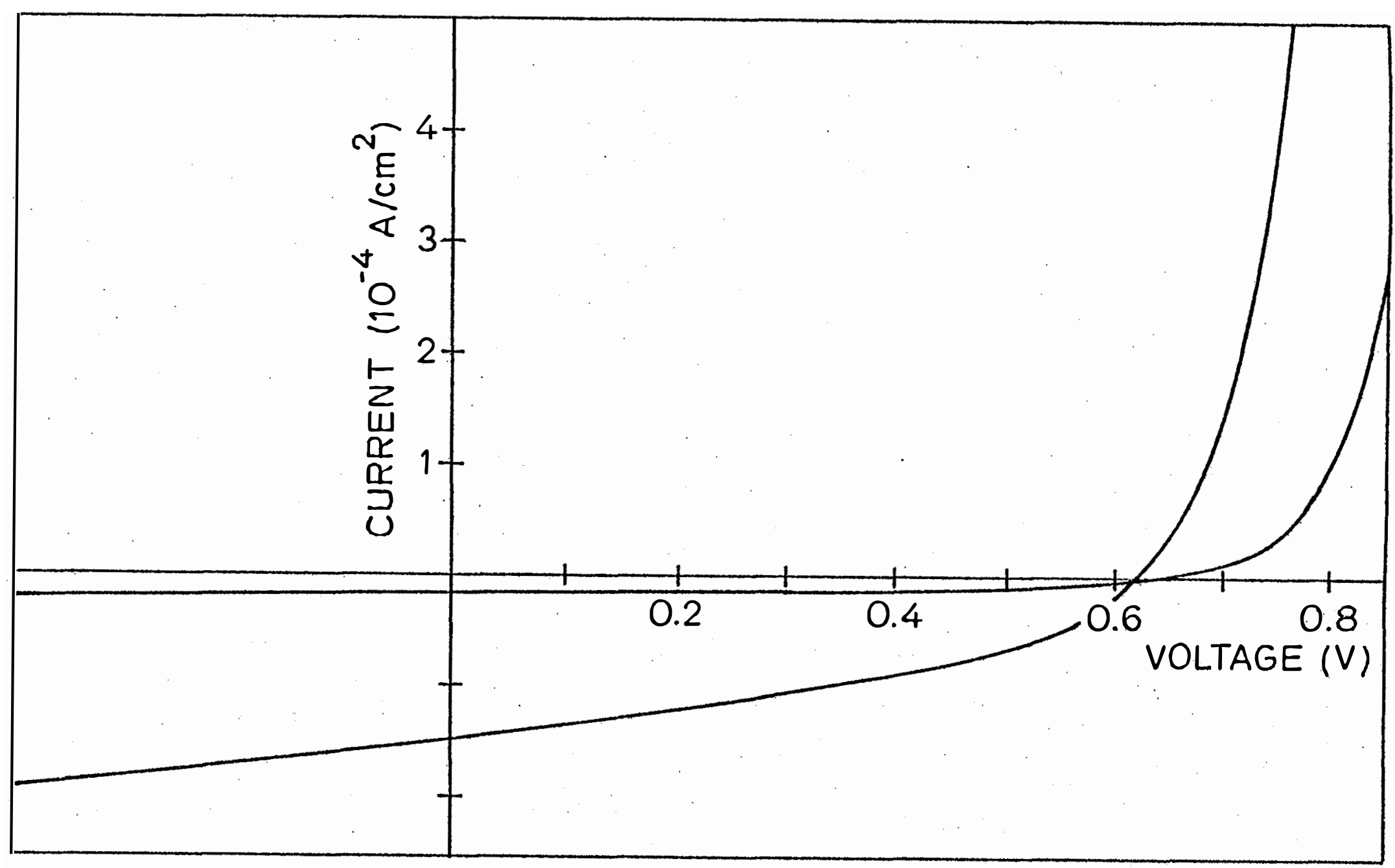

Figure 3. Light and dark $\mathrm{J}-\mathrm{V}$ curves on CdTe homojunction. $\mathrm{V}_{\mathrm{oc}}=0.62 \mathrm{~V}$, $\mathrm{J}_{\mathrm{sc}}=0.15 \mathrm{~mA} / \mathrm{cm}^{2}$ because of the thick $\mathrm{n}$-type layer used. 


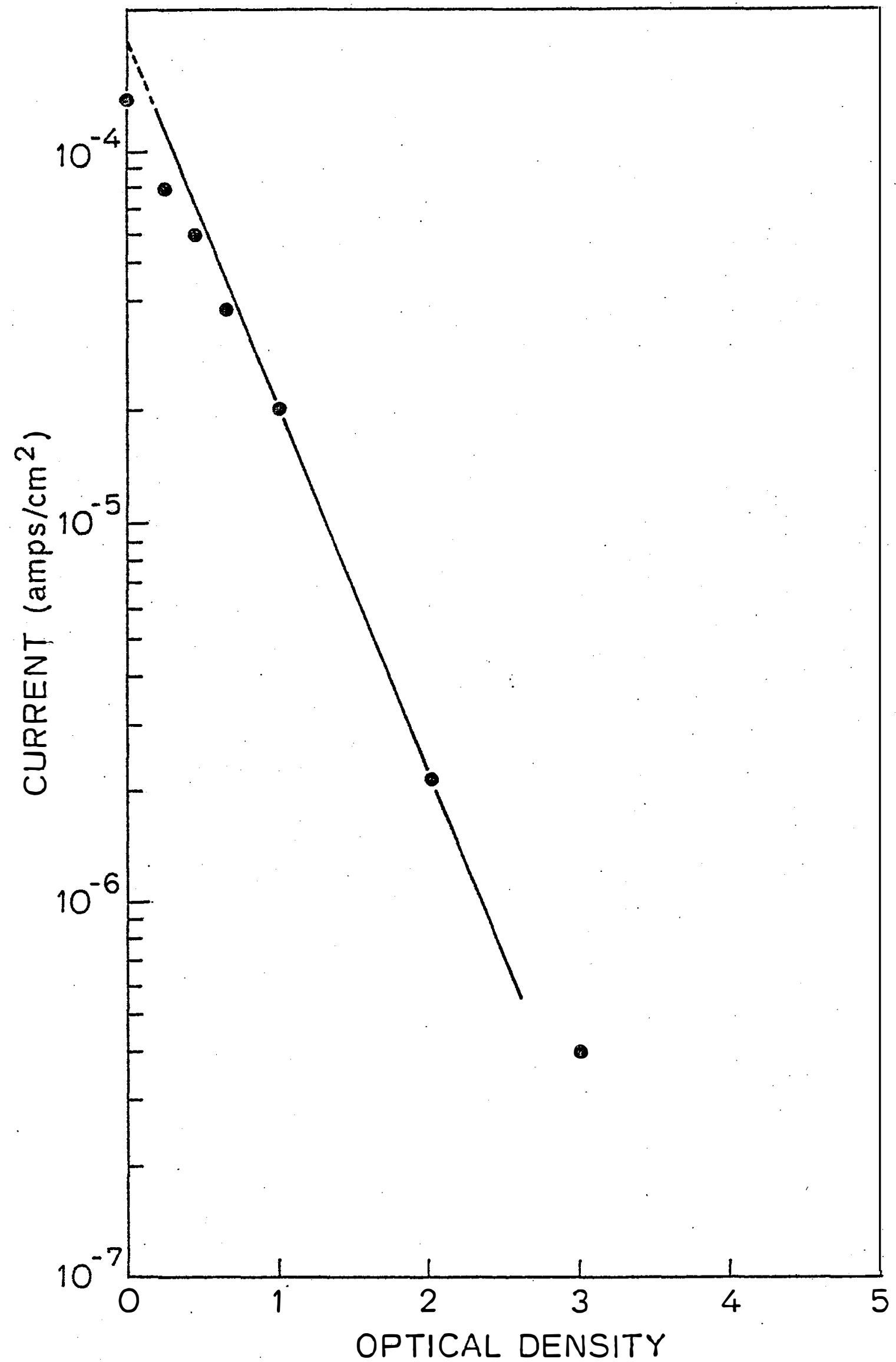

Figure 4. Test of the linearity of light current with light intensity. 
Electron Beam Induced Currents (EBIC)

EBIC techniques can be used to obtain minority carrier diffusion lengths. In our experiments the electron beam was incident on a cleaved edge of the junction, which was normal to the plane of the junction as shown in Figure 5. The beam is scanned across the cleaved surface producing electron-hole pairs in a small volume. The junction barrier collects the minority carriers to produce a current that is amplified and recorded as a function of position on photographic film, as shown in Figure 6. To a good approximation, the current is given by

$$
J \sim J_{0} \exp (-x / L)
$$

where $\mathrm{L}$ is the minority carrier diffusion length and $\mathrm{x}$ is the distance to the junction from the beam position.

Figure 7 shows a plot of $\ln \left(J / J_{0}\right)$ vs $x$; an ideal fit to the data in the p-type substrate is obtained, and an ideal fit within a few micrometers of the junction is also obtained in the n-type material. As the beam moves away from the junction in the n-type layer and approaches the front surface of the cell, an additional number of carriers is lost to front surface recombination. The effect of surface recombination on the cleaved surface normal to the junction plane is thought to be relatively small; its influence on the diffusion length will be determined by future measurements. The minority carrier diffusion length measured in this way gives average values of $1.8 \mu \mathrm{m}$ for electrons in the bulk CdTe and $1.2 \mu \mathrm{m}$ for holes in the n-type CdTe layer deposited by HWVE. These values are in good agreement with the spectral response modeling described later. 


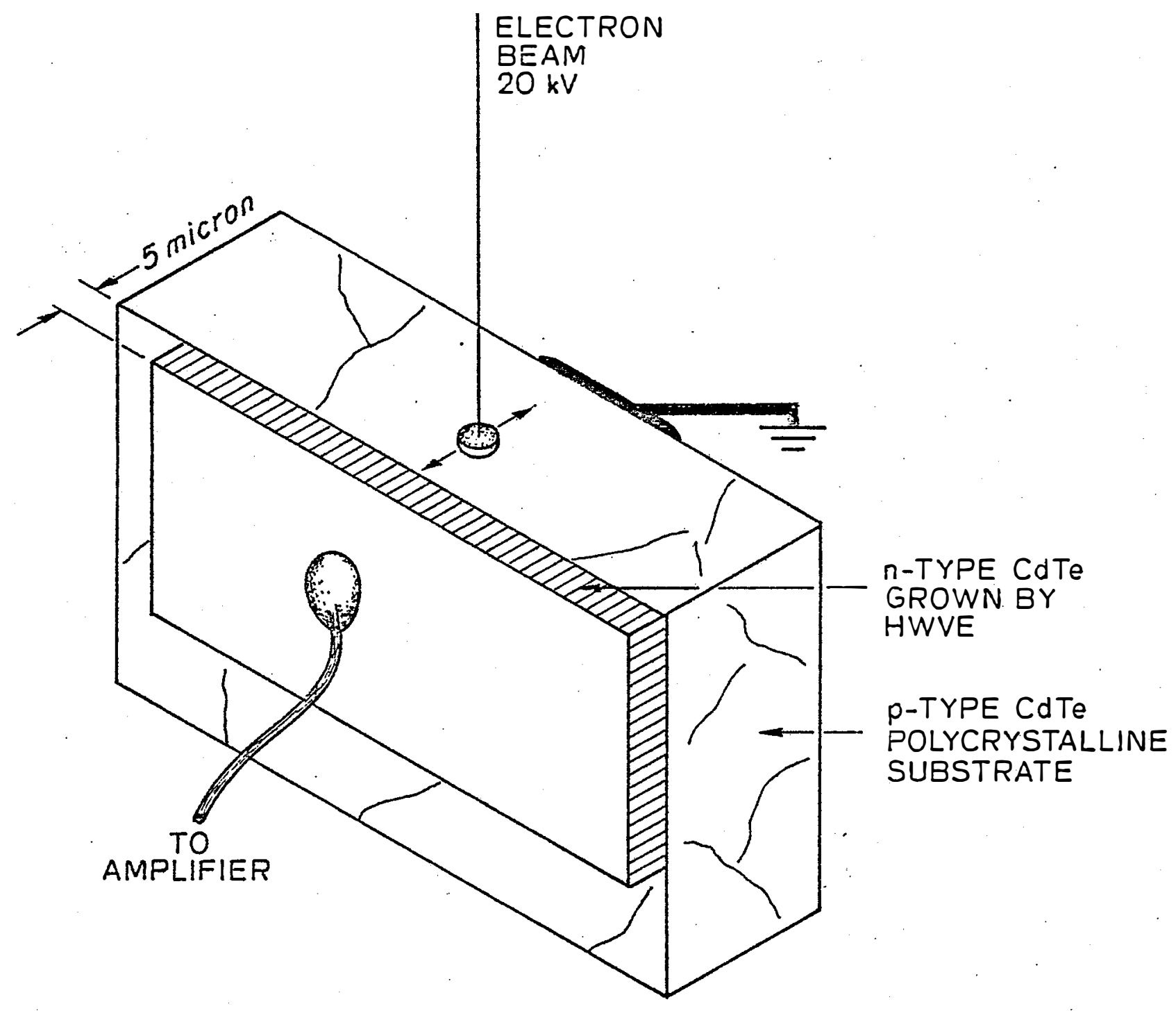

Figure 5. Geometry for an EBIC measurement. 


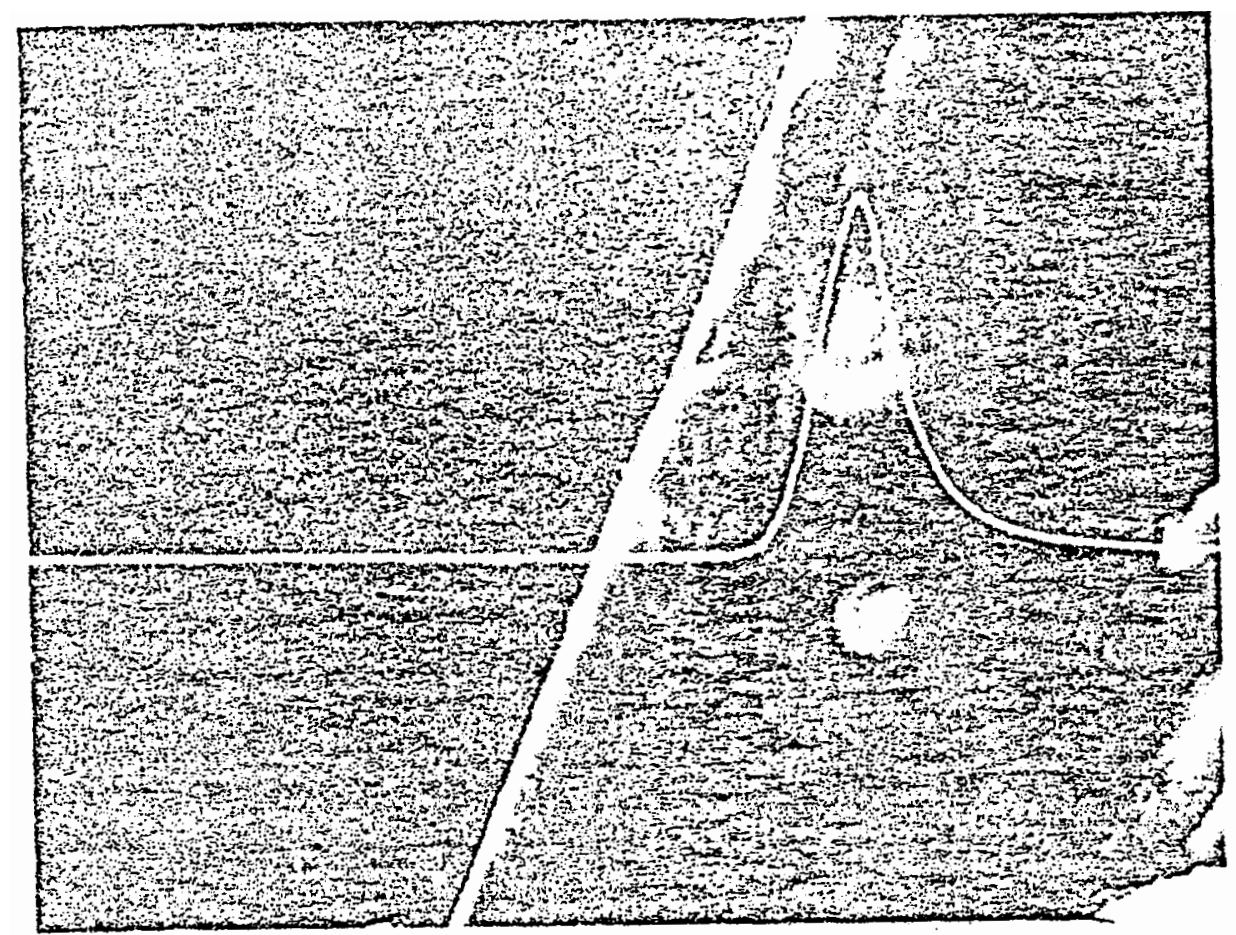

Figure 6. EBIC trace used to determine minority carrier lengths. 


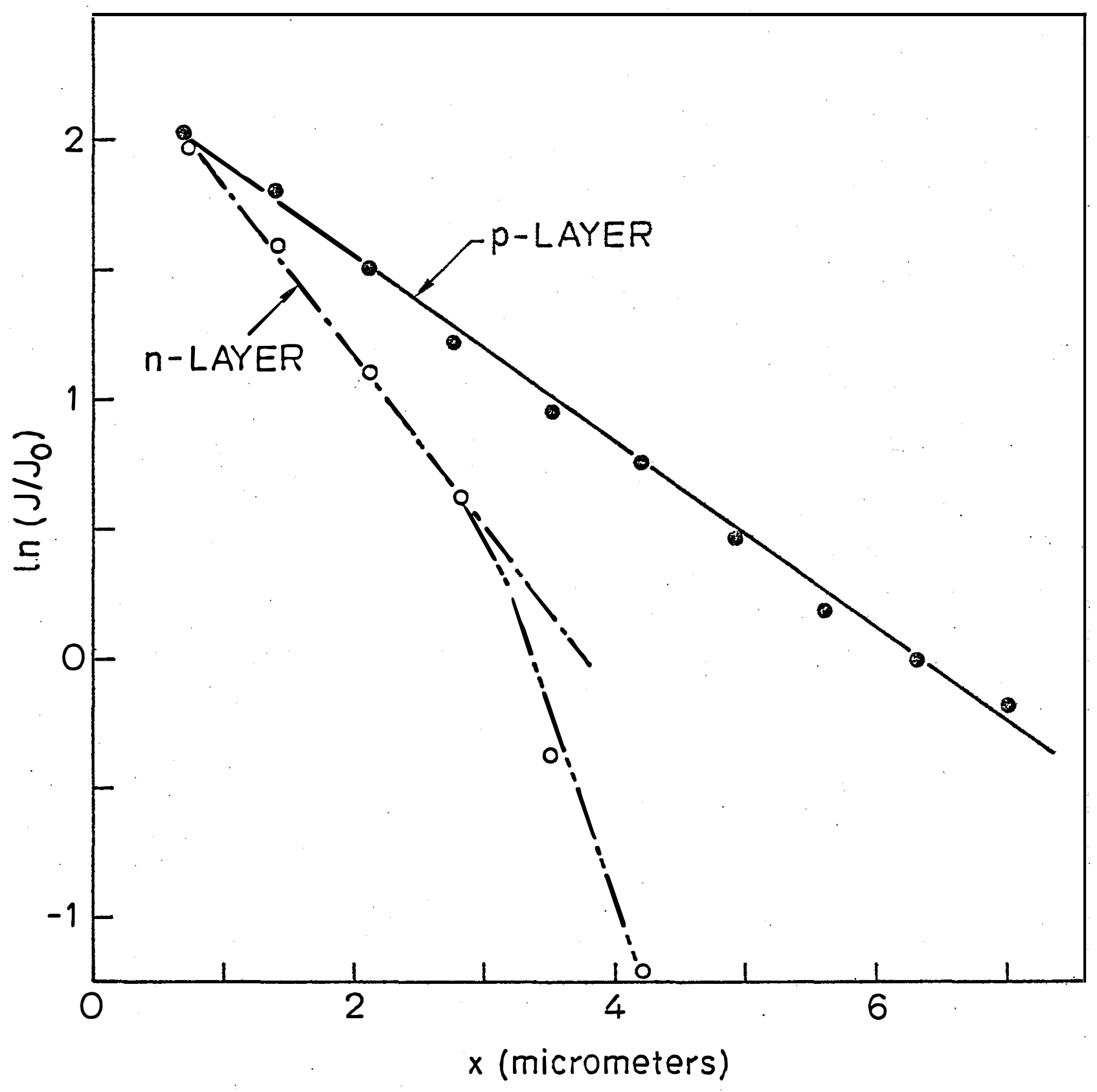

Figure 7. Determination of minority carrier lengths in $n$ - and p-type CdTe from EBIC data. 
Spectral Response

Spectral response measurements made on this solar cell indicated a peak quantum efficiency of about $2.8 \%$ at $825 \mathrm{~nm}$. The thick $(5 \mu \mathrm{m})$ n-type layer allows accurate determination of the coefficient of optical absorption at the longer wavelengths; since response is essentially independent of front-surface recombination effects, a reduction in the number of variables determining the spectral response is achieved.

Theoretical expressions for the light-generated current $J_{L}$ as given by Hovel ${ }^{1}$ have the following forms for holes in the n-type layer $\left(J_{L p}\right)$, carriers in the depletion layer $\left(J_{L W}\right)$, and electrons in the $\mathrm{p}$-type material $\left(\mathrm{J}_{\mathrm{Ln}}\right)$ :

$J_{L p}=\left.\frac{q F(1-R)}{\alpha^{2} L_{p}^{2}-1}\right|_{-} ^{\left(S_{p} L_{p} / D_{p}+\alpha L_{p}\right)-\exp \left(-\alpha x_{j}\right)\left\{S_{p} L_{p} / D_{p} \cosh \left(x_{j} / L_{p}\right)+\sinh \left(x_{j} / L_{p}\right)\right\}}$ $\left.-\alpha L_{p} \exp \left(-\alpha x_{j}\right)\right]$

$J_{L W}=q F(1-R) \exp \left(-\alpha x_{j}\right)\{1-\exp (-\alpha W)\}$

$J_{\text {In }}=\frac{q F(1-R)}{1+1 / \alpha L_{n}} \quad \exp \left\{-\alpha\left(x_{j}+W\right)\right\}$

Eqs: (3) and (4) are generally valid, and Eq. (5) applies for $x_{p}>L_{n}$. $\mathrm{L}_{\mathrm{p}}$ and $\mathrm{L}_{\mathrm{n}}$ are the minority carrier diffusion lengths in the $\mathrm{n}$ - and $\mathrm{p}$-type material respectively. $x_{j}$ is the thickness of the $n$-type layer. $R$ is the reflection coefficient (taken as zero for our first order approximation). $S_{p}$ is the surface recombination velocity, and $\alpha$ is the optical absorption coefficient. 
The quantum efficiency is given by

$$
n_{Q}=\frac{J_{L p}+J_{L n}+J_{L W}}{q \Gamma}
$$

where $\Gamma$ is the incident photon flux. When the location of the maximum quantum efficiency with respect to photon energy for $x_{j}=5$ micrometers is examined, it is found that the location is most sensitive to the optical absorption for any reasonable values of $\mathrm{S}_{\mathrm{p}}, \mathrm{L}_{\mathrm{n}}, \mathrm{L}_{\mathrm{p}}$, and $\mathrm{D}_{\mathrm{p}}$. We were therefore able to determine that the absorption data given by Mitchell et al. ${ }^{2}$ (see Figure 8 ) is in good agreement with the analysis of this cell as shown in Figure 9.

The value of the quantum efficiency at wavelengths shorter than $825 \mathrm{~nm}$ for a cell with a front layer of this thickness is very sensitive to minority carrier diffusion length, unless one assumes an extremely low surface recombination velocity. By comparing values of calculated response for diffusion lengths $\mathrm{L}_{\mathrm{p}}=\mathrm{L}_{\mathrm{n}}=0.75 \mu \mathrm{m} ; \mathrm{L}_{\mathrm{p}}=1.0 \mu \mathrm{m}$ and $\mathrm{L}_{\mathrm{n}}=1.5 \mu \mathrm{m}$; with the experimental data, one finds (see Figure 10) that the curve produced by letting $\mathrm{L}_{\mathrm{p}}=1.0 \mu \mathrm{m}$ and $\mathrm{L}_{\mathrm{n}}=1.5 \mu \mathrm{m}$ gives the best fit. Since reflection has been arbitrarily set equal to zero, the fit would be better if a realistic reflection coefficient were assumed (which we plan to measure later). The diffusion length values of $\mathrm{L}_{\mathrm{p}}=1.0 \mu \mathrm{m}$ and $\mathrm{L}_{\mathrm{n}}=1.5 \mu \mathrm{m}$ are conservative values based on our EBIC measurements.

Using the above parameters calculations can be made for an optimized CdTe homojunction with an n-type layer $0.3 \mu \mathrm{m}$.thick. Figure 11 shows the variation of quantum efficiency for such a cell as a function of depletion layer width, and Figure 12 shows similar curves for the dependence of quantum efficiency on $S_{p}$, the front surface recombination velocity. 


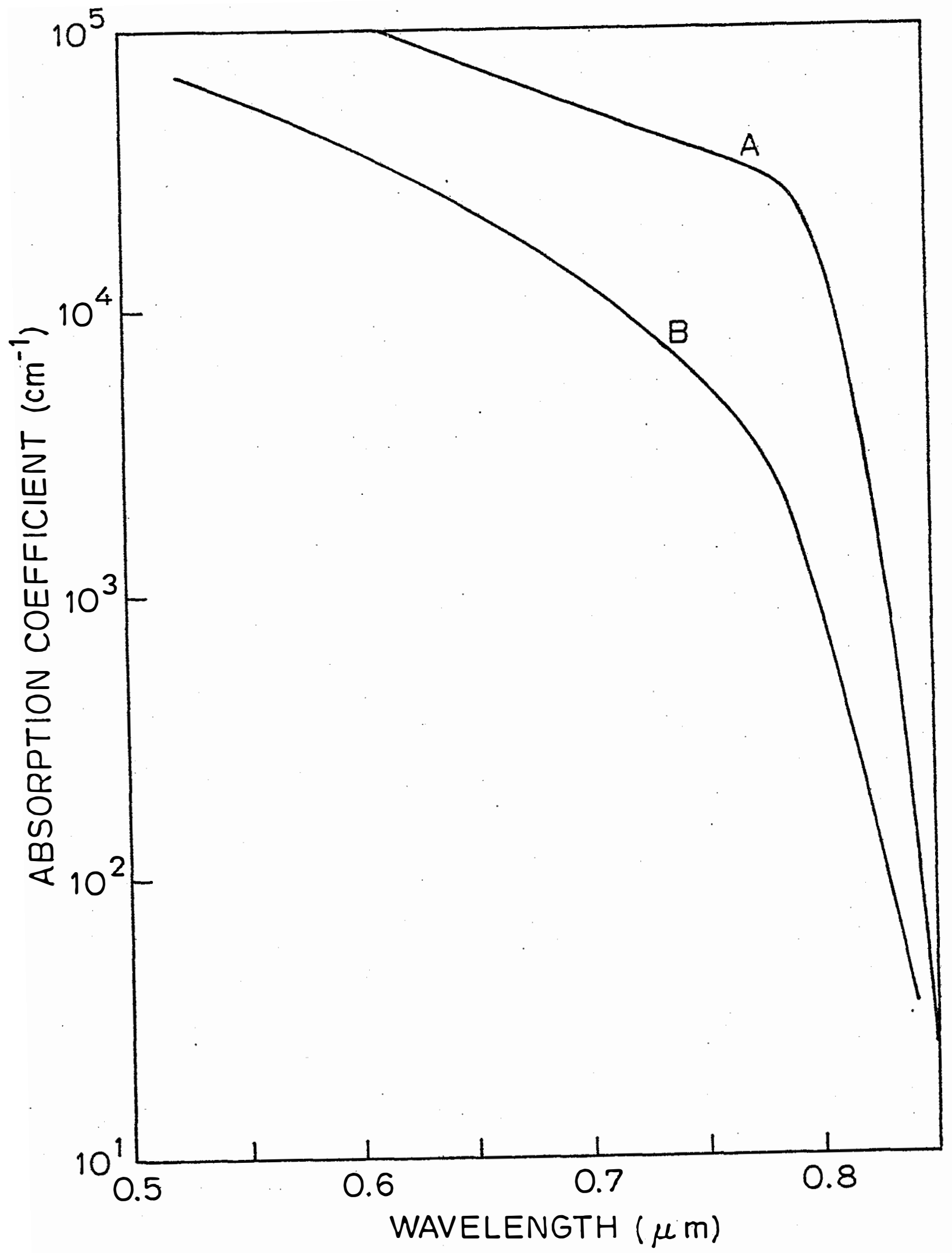

Figure 8. Absorption of CdTe. Curve A: evaluated by K.Mitchell, A.L. Fahrenbruch and R.H.Bube, J.App1.Phys. 48, 829 (1977).

Curve B: reported by P.Rappaport and J.J.Wysocki, Acta Electron. $\underline{5}, 364$ (1961) 


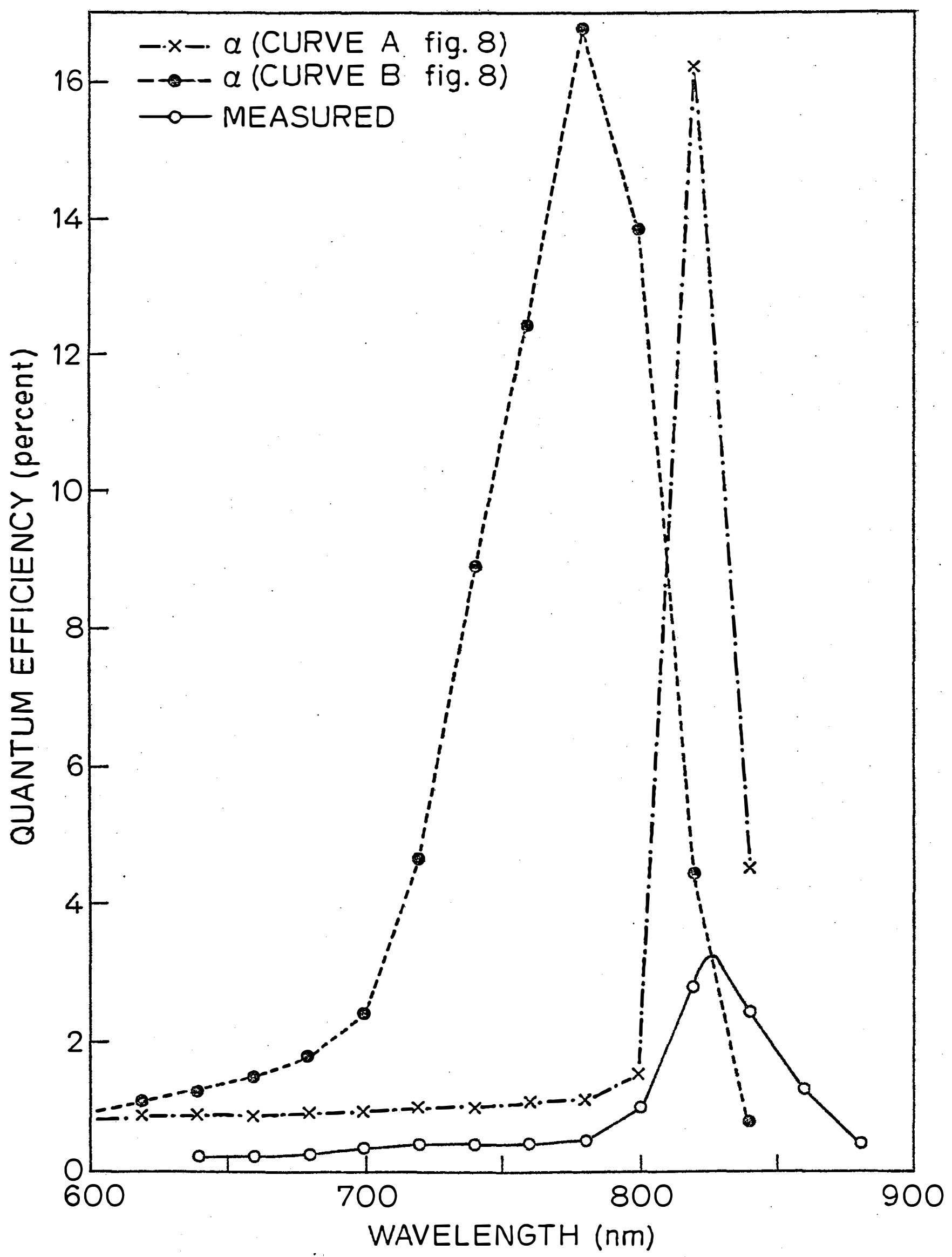

Figure 9. Comparison of theoretical curves of junction spectral response using absorption curves $A$ and $B$ of Figure 8, with experimental 


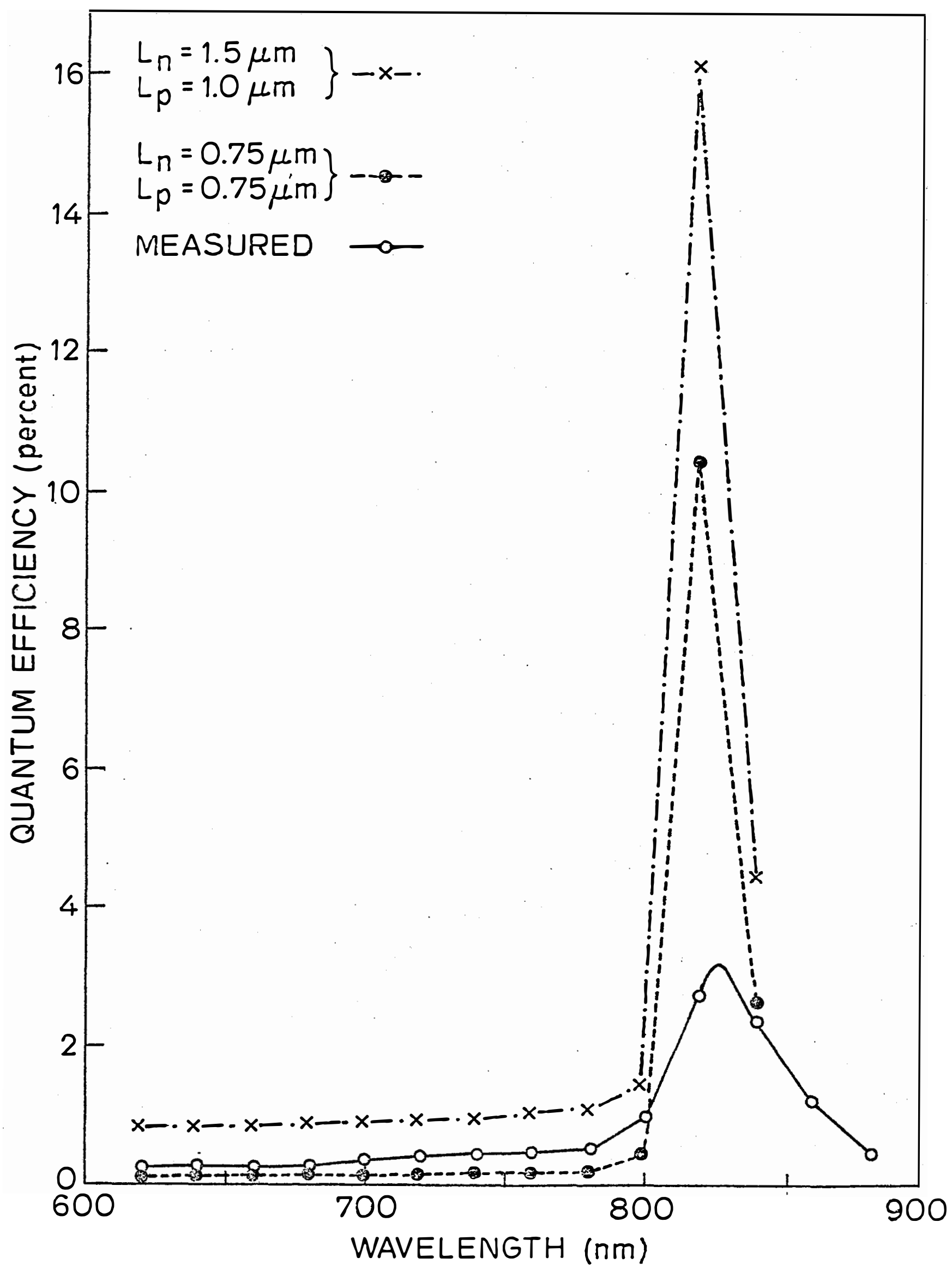

Figure 10. Comparison of theoretical curves with indicated diffusion lengths with experimentally measured spectral response. 


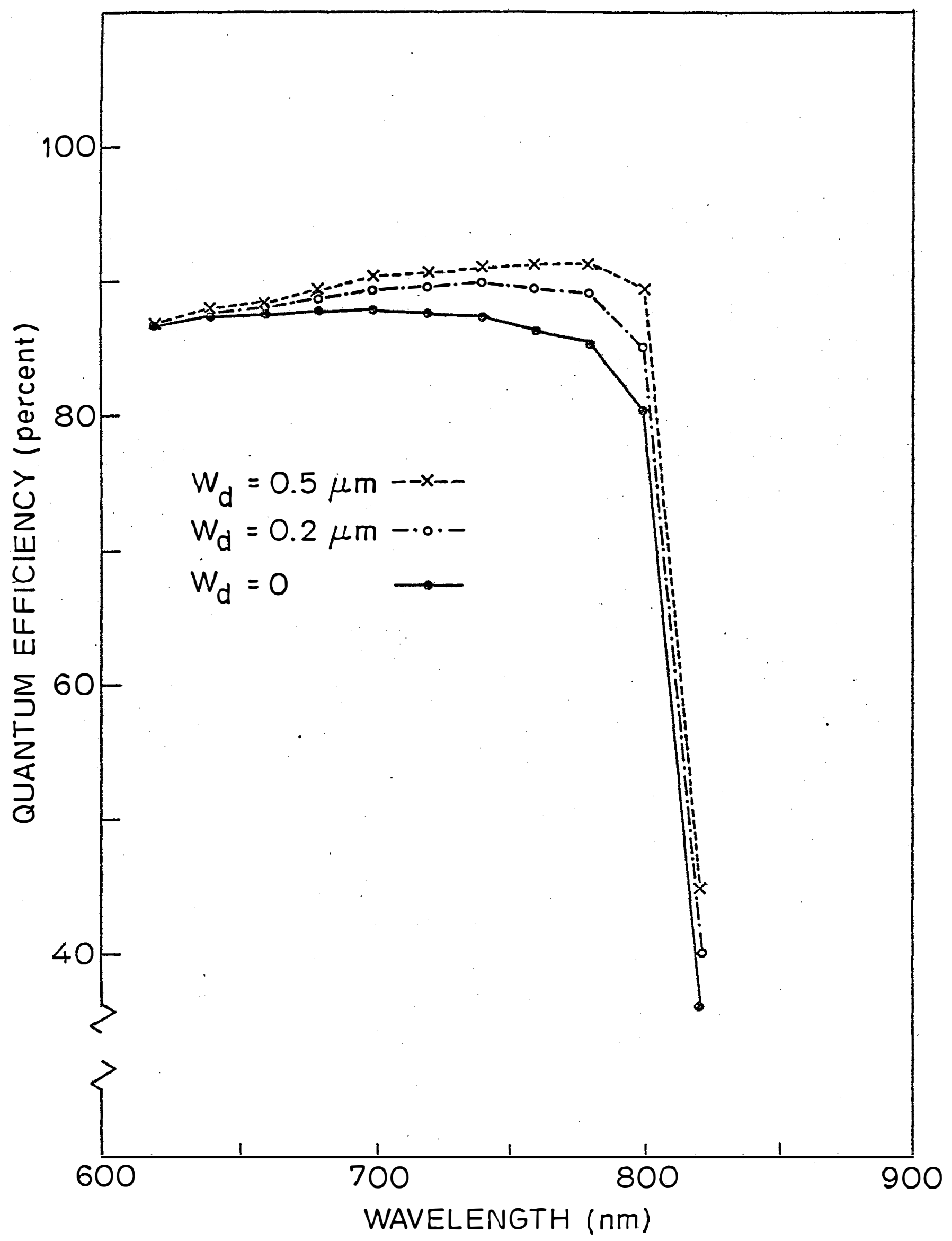

Figure 11. Variation of quantum efficiency with depletion layer width in an optimized cell with n-type layer $0.3 \mathrm{um}$ thick and $\mathrm{s}=10^{6} \mathrm{~cm} / \mathrm{sec}$. 


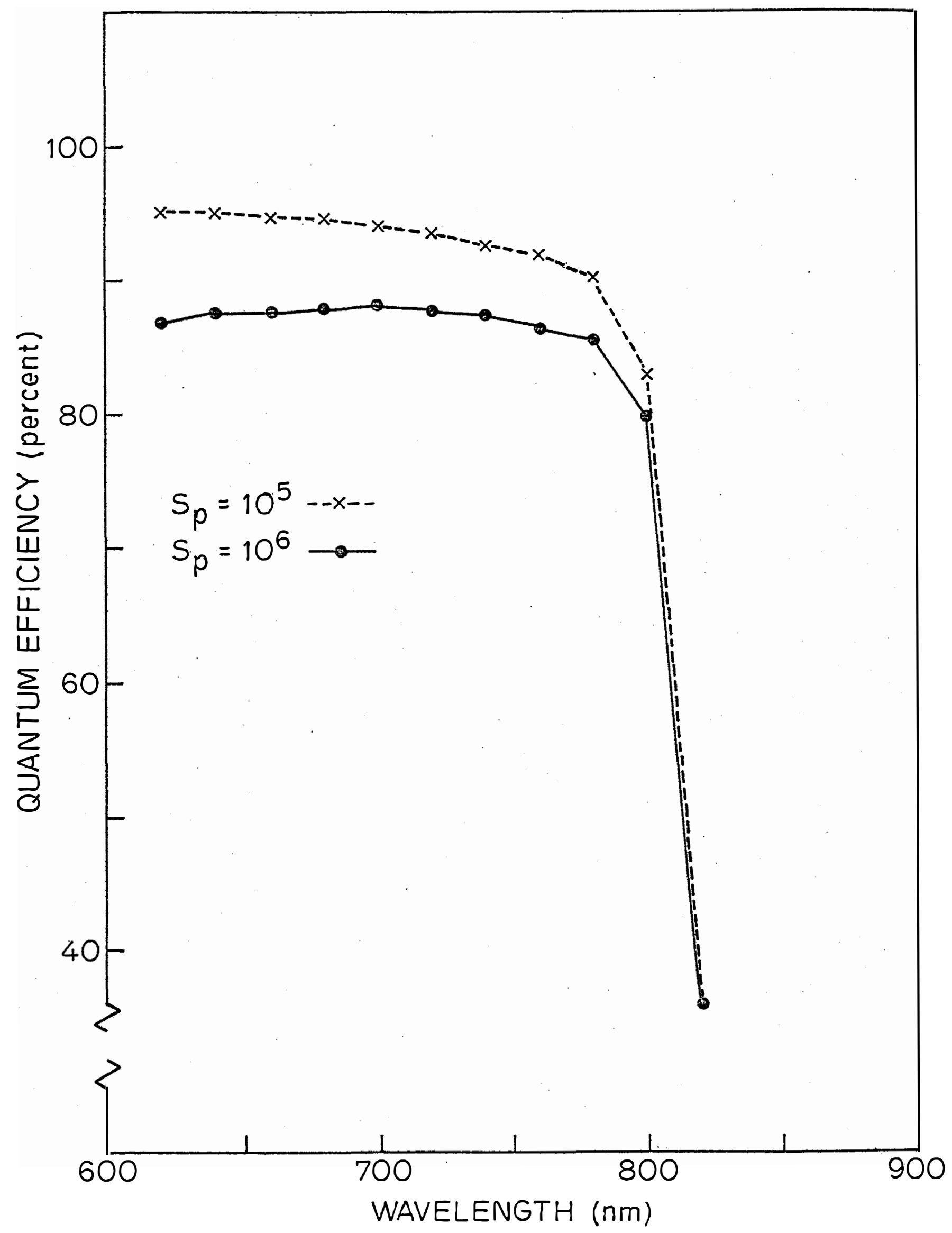

Figure 12. Variation of quantum efficiency with surface recombination velocity in an odtimiged rel1 with n-tvno lavor $n 3 \mathrm{um}$ thint and $\mathrm{k}=\mathrm{n}$ 
HOT-WALL VACUUM EVAPORATION SYSTEM

Figure 13 shows the hot-wall vacuum evaporation system design that has evolved after an analysis of systems in current use and an incorporation of several improvements. The source material and it's vapor are in contact only with quartz or graphite. It is possible to use three source materials, e.g., CdTe, excess Cd, and a dopant. Each source region has its own temperature controller so that the partial pressure of each species can be controlled independently. A shutter is incorporated to allow the source chamber to be in equilibrium prior to the initial deposition, as is necessary for controlling the interface properties of heterojunctions and grown-junction homojunctions, or for depositing a film on a metallic substrate that is to act as an ohmic contact.

A representative temperature profile envisioned for the system is shown in Figure 14, assuming that $\mathrm{Sb}$ is used as a dopant (zone 3 ) and that excess $C d$ is required (zone 4 ).

It will be possible to have two of these deposition systems in one vacuum chamber, allowing the growth of $\mathrm{n}$ - and $\mathrm{p}$-type layers without exposure to atmosphere. 


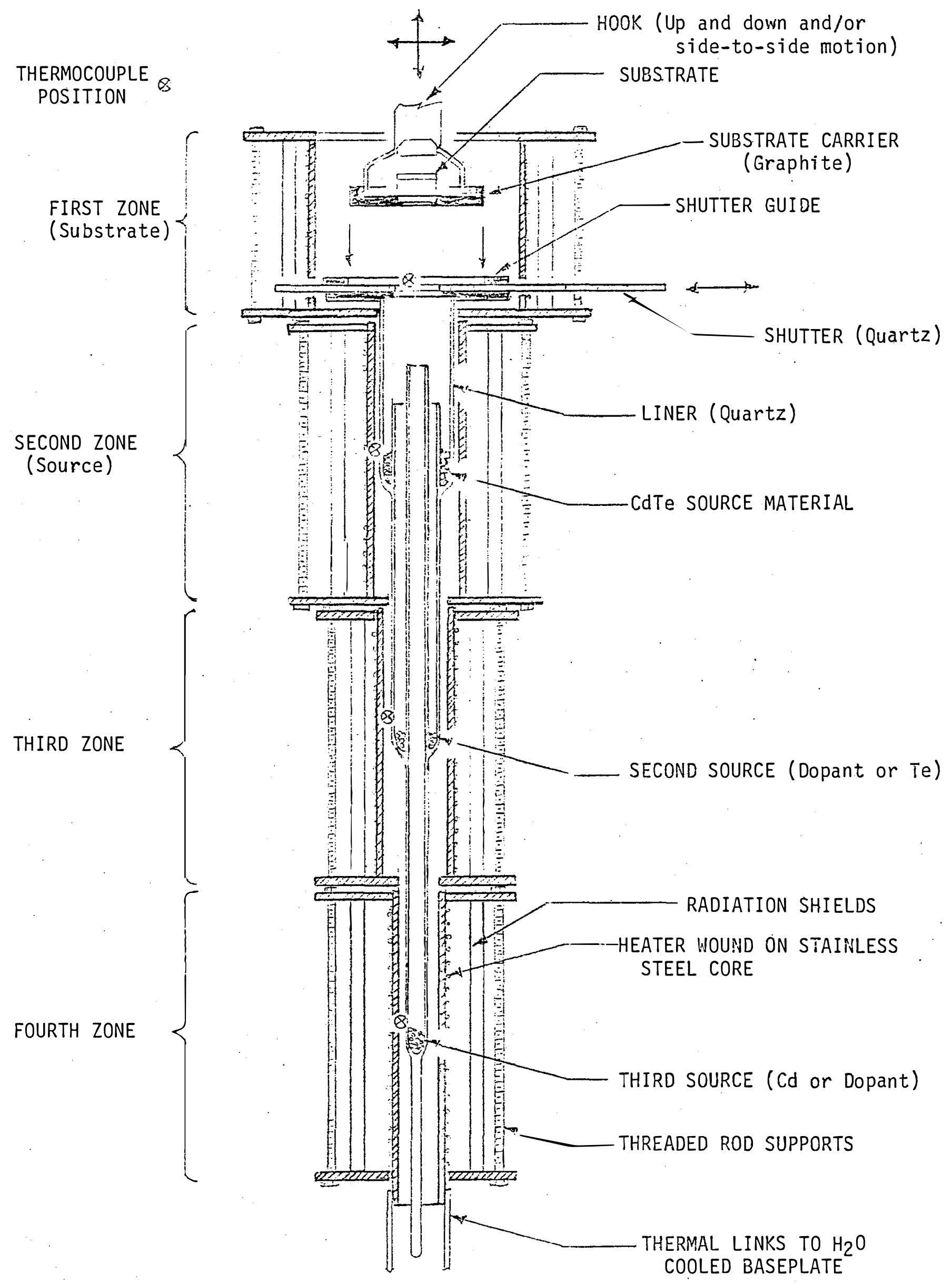

Fig. 13. Simplified schematic of Hot-Wall retort. Cover for first zone furnace (with attached radiation shielding) is not shown. 


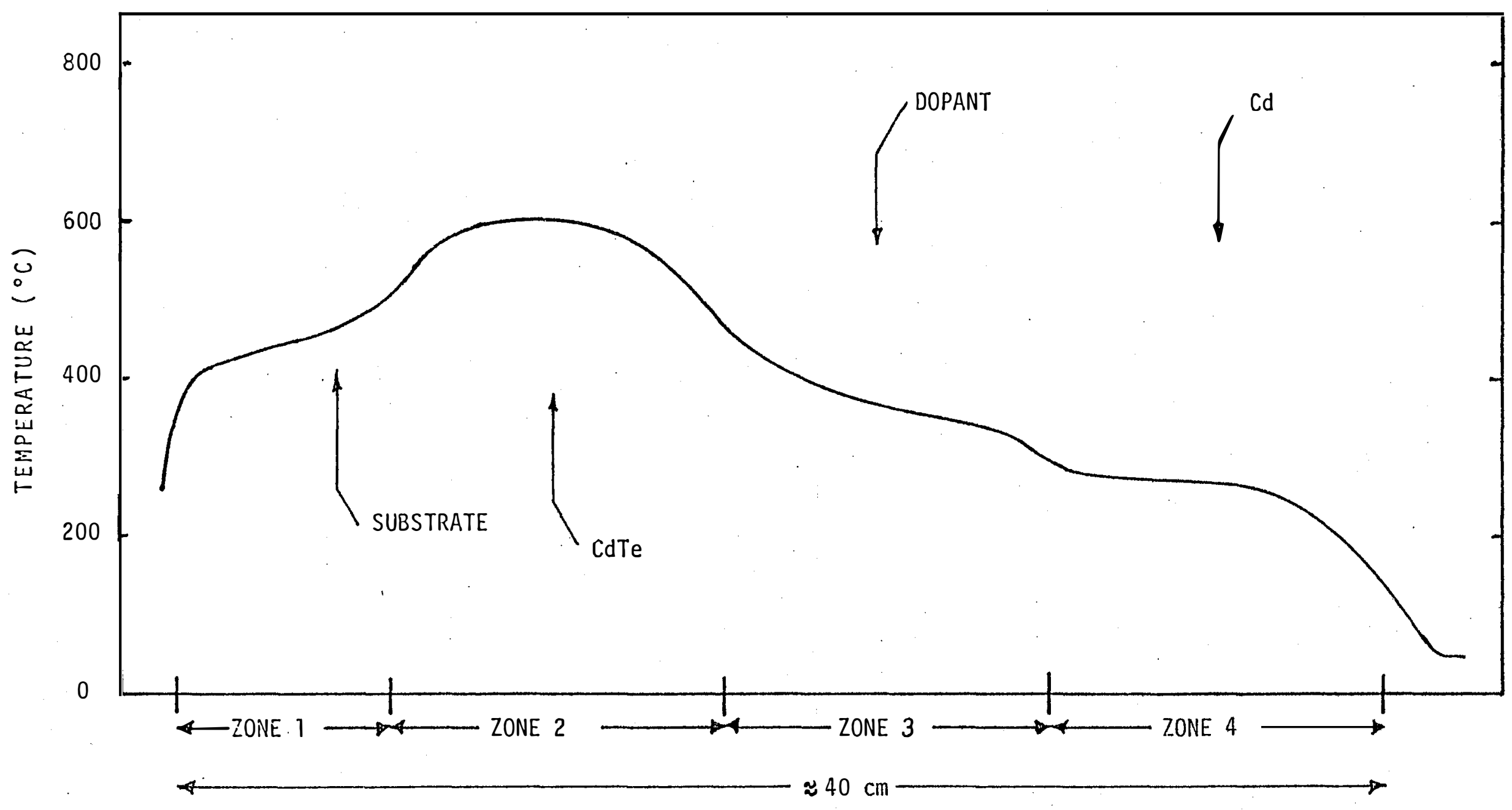

Fig. 14. Representative expected temperature profile for Hot-wall retort. 


\section{PROPERTIES OF GRAIN BOUNDARIES IN CdTe}

Initial measurements have been made on the properties of grain boundaries as a function of temperature and illumination, using conductivity, photoconductivity and photocapacitance techniques. All measurements reported here were made on samples cut from a single n-type polycrystalline boule of CdTe; the investigation will be applied ultimately to both $\mathrm{n}$ - and p-type CdTe.

Samples were cut with a single grain boundary perpendicular to a surface to which contact was made. The contact surface was polished with 1200 grit, and then etched in a 5\% bromine-methanol solution for approximately 5 minutes. To make ohmic contact indium dots were then annealed on the surface at $175^{\circ} \mathrm{C}$ for $10-15$ minutes. Resistivity measurements were made with a four-point technique. Values of bulk resistivity, not including grain boundaries, were in the range of 0.2 to $0.5 \mathrm{ohm}-\mathrm{cm}$.

Grain boundary barrier heights were measured by applying an electric field perpendicular to the boundary, and measuring the resistance of the sample as a function of temperature between $20^{\circ}$ and $150^{\circ} \mathrm{C}$. Figure 15 shows typical temperature variation of the grain-boundary resistance measured in this way. If $R=R_{0} \exp \left(E_{B} / k T\right)$ is taken to describe the temperature dependence of the resistance with an effective barrier height $E_{B}$, the data given values of $E_{B}$ between 0.17 and $0.4 \mathrm{eV}$ for the three boundaries investigated.

The grain boundary resistance of several samples was also measured under illumination as a function of wavelength from $700 \mathrm{~nm}$ to $1600 \mathrm{~nm}$. Results were normalized with respect to light intensity by assuming a linear variation of resistance with intensity. No decrease in resistance was observed for wavelengths greater than $1200 \mathrm{~nm}$. 


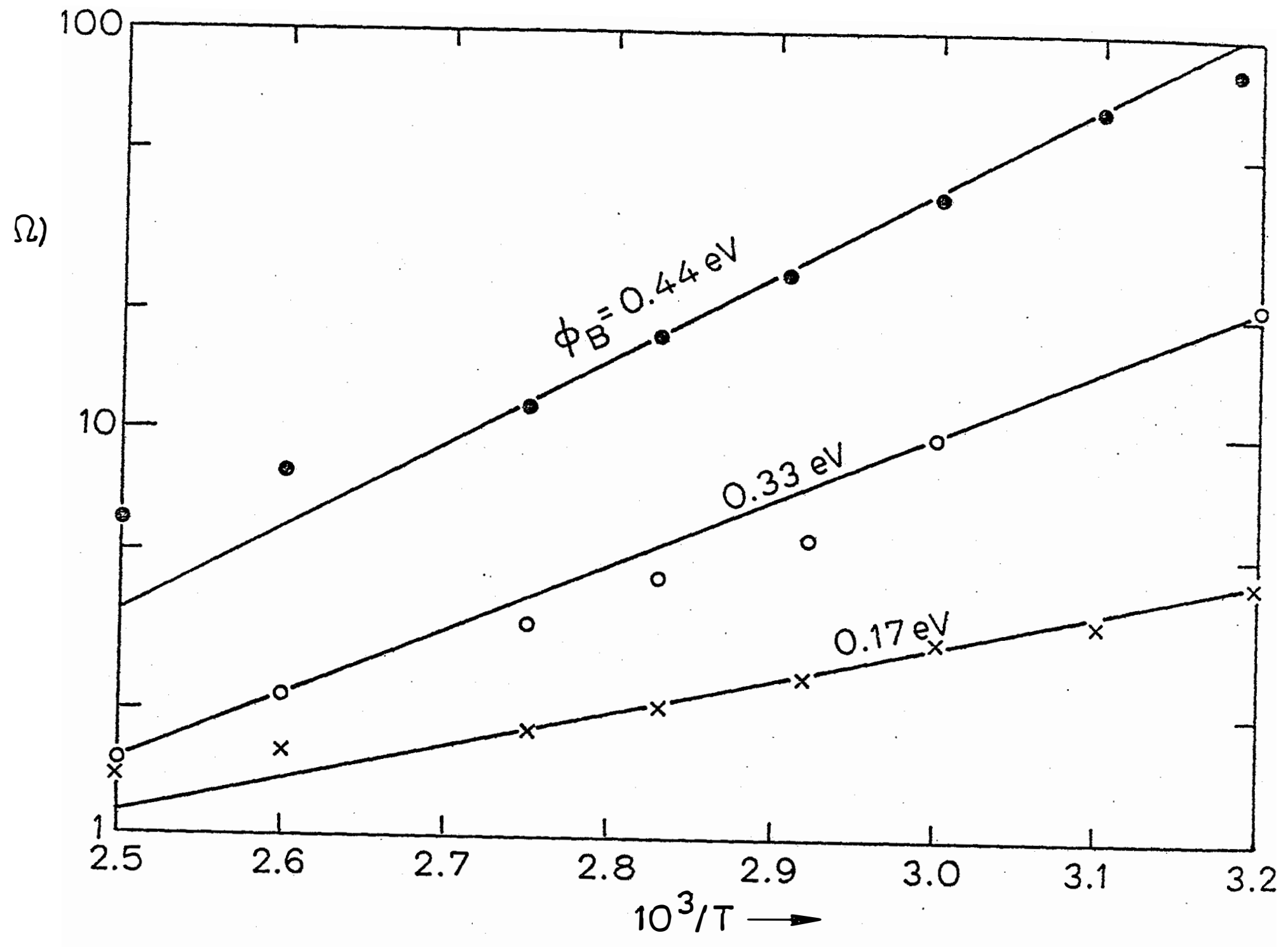

Figure 15. Grain boundary resistance for three samples of n-type CdTe as a function of temperature. 
The major effect occurred for light at the bandgap of CdTe, but in two of the samples photoeffects for wavelengths between 850 and $1200 \mathrm{~nm}$ were also observed. Photocapacitance measurements were made to determine the capacitance of the grain boundary as a function of wavelength; the spectral response was similar to that found for the resistance. The capacitance went to zero for bandgap illumination for all the samples measured. An initial measurement of $1 / C^{2}$ vs $V$ yielded a non-linear relationship. Initial attempts have been made to determine grain orientations using $\mathrm{X}$-ray diffraction, and diffusion length of minority carriers near a grain boundary using EBIC. Both of these investigations will be carried out in detail in the future.

The investigation of grain boundary properties in CdTe crystals appears to be a rich field for attack. Fairly simple measurements appear capable of giving useful information about grain boundary properties. We plan also to explore possible grain boundary passivation or inversion. 


\section{REFERENCES}

1. H. J. Hovel, Semiconductors and Semimetals, Vol. 11, Solar Cells, Academic Press, N.Y. (1975)

2. K. W. Mitchell, A. L. Fahrenbruch and R. H. Bube, J. App1. Phys. $48,829(1977)$ 
(29 Copies)

Solar Energy Research Institute Photovoltaics Program Office PVPO - Documentation 1617 Cole Boulevard Golden, C0 80401

Solar Energy Research Institute Contracts Branch

Ref.: EG-77-C-01-4042

1617 Cole Boulevard

Golden, C0 80401

Department of Energy

Technical Information Center

P.0. Box 62

Oakridge, Tennessee 37830

Department of Energy

Chicago Operations Office

Attn: Office of Public Affairs

9800 South Cass Avenue

Arogonne, Illinois 60539

Boeing Aeorspace Company

Attn: Dr. Reid A. Mikelsen

P.0. Box 3999

Seattle, Washington 98124

Joint Center for Graduate Study

University of Washington

Attn: Dr. Larry C. 01 son

Richland, WA 99352

The Pennsylvania State University

Attn: Dr. K. Vedam

276 Materials Research Laboratory

University Park, PA 16802
Radiation Monitoring Devices, Inc.

Attn: Dr. Geral Entine

44 Hunt St.

Watertown, MA 02172

Hughes Research Laboratories

Attn: Dr. Ken Zanio

3011 Malibu Canyon Rd.

Malibu, CA 90265

Allen Postlethwaite

Dept. of Energy

Washington, D.C. 20045

Research Triangle Institute

Attn: Dr. J. Edward Andrews

P.0. Box 12194

Research Triangle Park, North Carolina 277C

Southern Methodist University

Attn: Dr. Tin L. Chu

Dallas Texas 75275

Virginia Polytechnic Institute and State University

Research Division

Attn: Dr. Larry C. Burton

346 Whittemore Hall

Blacksburg, Virginia 24061

Wayne State University

Attn; Dr. Dan Trivich

Department of Chemistry

Detroit, Michigan 48202

University of Delaware

Institute of Energy Conversion

Attn: Dr. Tony Catalano

One Pike Creek Center

Wilminton, Delaware 19808 